\title{
Zymographic techniques for the analysis of matrix metalloproteinases and their inhibitors
}

\author{
Patricia A.M. Snoek-van Beurden and Johannes W. Von den Hoff
}

BioTechniques 38:73-83 (January 2005)

\begin{abstract}
The balance between matrix metalloproteinases (MMPs) and their inhibitors, the tissue inhibitors of metalloproteinases (TIMPs), is largely responsible for the remodeling of tissues. Deregulation of this balance is a characteristic of extensive tissue degradation in certain degenerative diseases. To analyze the role of MMPs and TIMPs in tissue remodeling under normal and pathological conditions, it is important to have reliable detection methods. This review will focus on zymographical techniques for the analysis of MMPs and TIMPs. MMPs can be analyzed with several zymographical techniques, but substrate zymography is the most commonly used. This technique identifies MMPs by the degradation of their preferential substrate and by their molecular weight. Several substrates that can be used for zymography are described. Reverse zymography, which detects TIMPs by their ability to inhibit MMPs, is also discussed. Finally, in situ zymography is described, which is used to localize MMPs in tissue sections. Common problems encountered during sample preparation, zymography itself, and the data analysis are discussed. Hints are given to improve the sensitivity and accuracy of zymographical methods. In conclusion, zymography is a valuable tool for research purposes and for the development of new diagnostic techniques and therapies for pathological conditions such as rheumatoid and osteoarthritis, and tumor progression.
\end{abstract}

\section{INTRODUCTION}

Matrix metalloproteinases (MMPs) are a family of calcium-dependent, zinc-containing endopeptidases that are structurally and functionally related (1). They are secreted in an inactive (latent) form, which is called a zymogen or a pro-MMP. These latent MMPs require an activation step before they are able to cleave extracellular matrix (ECM) components (1). The activity of MMPs is regulated by several types of inhibitors, of which the tissue inhibitors of metalloproteinases (TIMPs) are the most important (2). The TIMPs are also secreted proteins, but they may be located at the cell surface in association with membrane-bound MMPs (3). The balance between MMPs and TIMPs is largely responsible for the control of degradation of ECM proteins (4). MMPs are involved in the remodeling of tissues during embryonic development, cell migration, wound healing, and tooth development (5-8). However, a deregulation of the balance between MMPs and TIMPs is a characteristic of diverse pathological conditions, such as rheumatoid and osteoarthritis, cancer progression, and acute and chronic cardiovascular diseases $(3,9,10)$. To analyze the role of MMPs and TIMPs in tissue remodeling under normal and pathological conditions, it is important to have reliable detection methods. This review will briefly describe all known MMPs, their activation, and their role in tissue remodeling and pathology. It will focus on zymographical techniques for the analysis of MMPs and TIMPs.

\section{THE MMP FAMILY}

The family of human MMPs consists of 23 different forms that are divided into six groups (11-14). In order to classify the MMPs, knowledge of their characteristics is essential. It has been shown that each MMP consists of a specific domain sequence with several domain motifs. This sequence includes the signal peptide, the propeptide domain, the catalytic domain, and the C-terminal hemopexin-like domain, which are present in almost all MMPs (15). However, several MMPs have additional domains such as a transmembrane or a cytoplasmic domain $(15,16)$. The organization of the MMP domains, together with their substrate specificity and sequence similarity, define the MMP classification. Six groups can be distinguished (Table 1; subgroups 1-6). (1.) The collagenase group includes MMP-1, MMP-8, and MMP-13. These are generally able to cleave the interstitial collagens I, II, and III. Collagenases are also able to digest certain other ECM and nonECM proteins $(8,12,17)$. (2.) The gelatinase group, which consists of MMP-2 and MMP-9, mainly digests gelatin, the denatured form of collagen $(8,12)$. (3.) The stromelysins, MMP-3 and MMP-10, digest ECM components such as collagen IV and fibronectin. MMP-11 is also called stromelysin-3, but its sequence and substrate specificity are different from that of MMP-3 and MMP-10. Therefore, MMP-11 is usually placed in the heterogeneous subgroup (see subgroup 6) $(8,12,17)$. (4.) The matrilysins, MMP-7 and MMP-26, which are categorized differently among the MMP subgroups by 
Table 1. Members of the MMP Family

\begin{tabular}{|c|c|c|c|}
\hline Subgroup & MMP & Name & Substrate \\
\hline 1. Collagenases & $\begin{array}{l}\text { MMP-1 } \\
\text { MMP-8 } \\
\text { MMP-13 }\end{array}$ & $\begin{array}{l}\text { Collagenase-1 } \\
\text { Collagenase-2 } \\
\text { Collagenase-3 }\end{array}$ & $\begin{array}{l}\text { Col I, II, III, VII, VIII, X, gelatin } \\
\text { Col I, II, III, VII, VIII, X, aggrecan, gelatin } \\
\text { Col I, II, III, IV, IX, X, XIV, gelatin }\end{array}$ \\
\hline 2. Gelatinases & $\begin{array}{l}\text { MMP-2 } \\
\text { MMP-9 }\end{array}$ & $\begin{array}{l}\text { Gelatinase A } \\
\text { Gelatinase B }\end{array}$ & $\begin{array}{l}\text { Gelatin, Col I, II, III, IV, VII, X } \\
\text { Gelatin, Col IV, V }\end{array}$ \\
\hline 3. Stromelysins & $\begin{array}{l}\text { MMP-3 } \\
\text { MMP-10 } \\
\text { MMP-11 }\end{array}$ & $\begin{array}{l}\text { Stromelysin-1 } \\
\text { Stromelysin-2 } \\
\text { Stromelysin-3 }\end{array}$ & $\begin{array}{l}\text { Col II, IV, IX, X, XI, gelatin } \\
\text { Col IV, laminin, fibronectin, elastin } \\
\text { Col IV, fibronectin, laminin, aggrecan }\end{array}$ \\
\hline 4. Matrilysins & $\begin{array}{l}\text { MMP-7 } \\
\text { MMP-26 }\end{array}$ & $\begin{array}{l}\text { Matrilysin-1 } \\
\text { Matrilysin-2 }\end{array}$ & $\begin{array}{l}\text { Fibronectin, laminin, Col IV, gelatin } \\
\text { Fibrinogen, fibronectin, gelatin }\end{array}$ \\
\hline 5. MT-MMP & $\begin{array}{l}\text { MMP-14 } \\
\text { MMP-15 } \\
\text { MMP-16 } \\
\text { MMP-17 } \\
\text { MMP-24 } \\
\text { MMP-25 }\end{array}$ & $\begin{array}{l}\text { MT1-MMP } \\
\text { MT2-MMP } \\
\text { MT3-MMP } \\
\text { MT4-MMP } \\
\text { MT5-MMP } \\
\text { MT6-MMP }\end{array}$ & $\begin{array}{l}\text { Gelatin, fibronectin, laminin } \\
\text { Gelatin, fibronectin, laminin } \\
\text { Gelatin, fibronectin, laminin } \\
\text { Fibrinogen, fibrin } \\
\text { Gelatin, fibronectin, laminin } \\
\text { Gelatin }\end{array}$ \\
\hline 6. Others & $\begin{array}{l}\text { MMP-12 } \\
\text { MMP-19 } \\
\text { MMP-20 } \\
\text { MMP-21 } \\
\text { MMP-23 } \\
\text { MMP-27 } \\
\text { MMP-28 }\end{array}$ & $\begin{array}{l}\text { Macrophage metalloelastase } \\
\text { Enamelysin } \\
\text { XMMP } \\
\text { CMMP } \\
\text { Epilysin }\end{array}$ & $\begin{array}{l}\text { Elastin, fibronectin, Col IV } \\
\text { Aggrecan, elastin, fibrillin, Col IV, gelatin } \\
\text { Aggrecan } \\
\text { Aggrecan } \\
\text { Gelatin, casein, fibronectin } \\
\text { Unknown } \\
\text { Unknown }\end{array}$ \\
\hline
\end{tabular}

several authors $(4,12,18,19)$. Both matrilysins digest several ECM components, such as fibronectin and gelatin (20). They lack the C-terminal hemopexin-like domain present in all other MMPs and are therefore also called the minimal-domain MMPs (16,21). (5.) The membrane-type matrix metalloproteinases (MT-MMP), of which six forms are known, can digest a number of ECM proteins such as gelatin, fibronectin, and laminin (22). Moreover, most MT-MMPs can activate pro-MMP-2 $(8,12)$. (6.) The remaining MMPs are gathered in a more heterogeneous subgroup because of their different substrate specificity, amino acid sequence, or domain organization. This group includes MMP-12, MMP-19, MMP-20, MMP-21, MMP23, MMP-27, and MMP-28 (8,12), which cleave substrates such as elastin and aggrecan $(23,24)$. The classification presented here is a general one, and several other classifications are used $(4,8,12,17)$. The main difference between these classifications is the assignment of the matrilysins, which are sometimes designated separately or to the stromelysins or the heterogeneous subgroup $(4,8,12,17)$.

In healthy tissues, some MMPs such as MMP-7, MMP-19, MMP-24, MMP25, and MMP-26 are expressed at low levels (25). Many of the other MMPs, such as MMP-1, MMP-3, MMP-9, MMP-10, MMP-11, and MMP-13 are absent or only marginally expressed in normal, healthy, resting tissues. During repair or remodeling processes and in diseased or inflamed tissues, MMP expression is often increased $(25,26)$.

\section{ACTIVATION OF MMPs}

MMP activity is regulated at multiple levels, such as at the level of gene transcription and the synthesis of pro-MMPs. Furthermore, the activation of proenzymes and the inhibition of MMPs by TIMPs are important regulatory processes. MMPs are secreted in a latent form as proMMPs, which require activation. In the propeptide domain of the MMPs, a cysteine residue $\left(\mathrm{Cys}^{73}\right)$ is present, which functions as a stabilizer of the inactive proenzyme $(27,28)$. In the catalytic domain, an active $\mathrm{Zn}^{2+}$ site is present, which forms a bond with the cysteine residue. When this $\mathrm{Cys}^{73}$ $\mathrm{Zn}^{2+}$ bond is intact, the MMP is inactive (Figure 1). The activation of MMPs involves a disruption of the bond between the active $\mathrm{Zn}^{2+}$ site and the cysteine residue. This mechanism has been referred to as the "cysteine switch" $(27,28)$. A water molecule then binds to the $\mathrm{Zn}^{2+}$ ion and replaces the cysteine residue after the dissociation (27). The noncatalytic zinc is then switched to a catalytic one, which results in an intermediate active enzyme (27). Additionally, the pro-domain of the MMP is removed by autolytic cleavage or by other proteases $(27,28)$. This cleavage causes a reduction in molecular mass and results in a fully active enzyme. The mass reduction is generally in the range of $8-10 \mathrm{kDa}$ (29). In vivo, MMPs are generally activated by other proteinases. In vitro, MMPs are also activated by chemical and physical agents such as aminophenylmercuric acetate (APMA), low $\mathrm{pH}$, and heat treatment $(12,15,27)$.

\section{THE ROLE OF MMPs IN NORMAL TISSUE REMODELING}

MMP activity is mainly regulated by TIMPs, of which four human forms are known that can inhibit almost all MMPs tested thus far. Moreover, the TIMPs do not seem to differentiate much between the various MMPs $(4,12)$. TIMPs have a high level of sequence heterogeneity, which suggests that they also have different functional properties (2). For instance, in addition to inhibiting MMP activity, TIMPs also seem to have growth factor-like and antiangiogenic properties (30). TIMPs generally inhibit the activity of MMPs by the formation of a 1:1 complex (12). 
Normal and pathological tissue remodeling is regulated by the balance of MMPs and TIMPs within the tissue (4). The remodeling of tissues is essential for several aspects of normal physiology, including embryonic development, collagen turnover, tooth development, and cell migration but also in processes like wound healing (5-7). For instance, during the embryonic development in mice, mRNA levels for MMP-9 and MMP-13 and TIMP-1 are highly expressed in bone. Additionally, in embryonic epithelial tissues, mRNA for TIMP-3 is widely expressed (6).

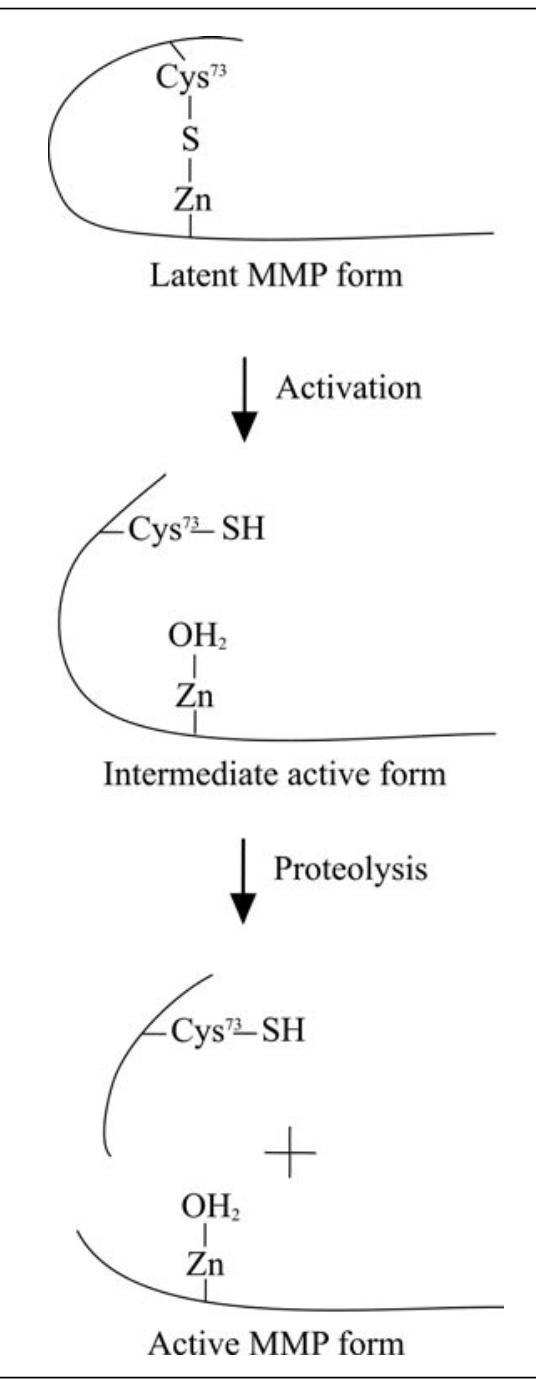

Figure 1. The activation of pro-MMPs. The activation of latent MMPs involves a disruption of the $\mathrm{Cys}^{73}-\mathrm{Zn}^{2+}$ bond that results in an intermediate active form. During zymography, the latent MMP unfolds due to SDS. The fully active MMP form is formed in vivo through proteolysis $(27,28)$. MMP, matrix metalloproteinase; SDS, sodium dodecyl sulfate.

\section{THE ROLE OF MMPS IN PATHOLOGICAL TISSUE REMODELING}

Numerous pathological conditions are caused by the disruption of the balance between MMPs and TIMPs (4). Overproduction of MMPs is associated with tissue destruction in chronic inflammatory diseases such as rheumatoid and osteoarthritis $(9,10)$. In both conditions, it appears that the erosion of cartilage is caused by an increased expression of MMPs such as MMP-1, MMP-8, and MMP-13, depending on the joint tested $(9,10)$. In addition, the contribution of each MMP to the disease process may vary in each joint (31). MMPs are also involved in tumor growth and metastasis (32). In almost all human cancers, the MMP expression and activity are increased. In colon cancer, mainly MMP-7 is overexpressed $(33,34)$. The increased levels of MMPs seem to correlate with invasiveness and poor prognosis (16). Deregulation of MMPs has also been implicated in distinct acute and chronic cardiovascular diseases, such as atherosclerosis, myocardial infarction, and heart failure $(35,36)$. Several MMPs such as MMP-1 and MMP-9 are also known to influence the process of atherosclerotic lesion formation, but the mechanism is still not completely elucidated (22).

Many different MMPs are involved in normal tissue remodeling but also play a role in tissue resorption in pathological conditions. To prevent tissue degradation by a disturbed MMPTIMP balance, it is important to know which MMPs and TIMPs are involved in the specific disease processes. Thus, the analysis of MMPs in biological samples can contribute to the characterization of certain diseases involving tissue destruction and possibly to the development of new therapies.

\section{DETECTION OF MMPS}

The expression of MMPs can be analyzed with several techniques. A widely used technique is substrate zymography, which identifies MMPs by the degradation of their preferential substrate and by their molecular weight.
Using this technique, one can determine whether the MMP is in an active or latent form. To localize MMPs in tissue sections, in situ zymography can be performed. TIMPs can be detected by reverse zymography, which is based on their ability to inhibit MMPs. These specific techniques will be discussed in the next sections.

\section{SUBSTRATE ZYMOGRAPHY}

Zymography and reverse zymography are described as simple, sensitive, quantifiable, and functional assays to analyze MMPs and TIMPs in biological samples $(37,38)$. All types of substrate zymography originate from gelatin zymography. The techniques are the same except that the substrate differs depending on the type of MMPs or TIMPs to be detected. In zymography, the proteins are separated by electrophoresis under denaturing [sodium dodecyl sulfate (SDS)], nonreducing conditions. The separation occurs in a polyacrylamide gel containing a specific substrate that is co-polymerized with the acrylamide $(39,40)$. During electrophoresis, the SDS causes the MMPs to denature and become inactive. The activation of latent MMPs during zymography is believed to involve the "cysteine switch" because the dissociation of $\mathrm{Cys}^{73}$ from the zinc molecule is caused by SDS (Figure 1; Reference 27). After electrophoresis, the gel is washed, which causes the exchange of the SDS with Triton ${ }^{\circledR} \mathrm{X}-100$, after which the enzymes partially renature and recover their activity $(39,41)$. Additionally, the latent MMPs are autoactivated without cleavage (42). Subsequently, the gel is incubated in an appropriate activation buffer. During this incubation, the concentrated, renatured MMPs in the gel will digest the substrate $(37,40)$. After incubation, the gel is stained with Coomassie ${ }^{\circledR}$ Blue, and the MMPs are detected as clear bands against a blue background of undegraded substrate $(37,40)$. The clear bands in the gel can be quantified by densitometry (41). Zymography is based on the following principles: (i) during electrophoresis, gelatin is retained in the gel; (ii) MMP activity is reversibly inhibited by SDS 
during electrophoresis; and (iii) the SDS causes the separation of MMPTIMP complexes during electrophoresis. This enables the detection of MMPs and TIMPs independently of one another (37). An additional advantage of zymography is that both the proenzymes and the active forms of MMPs can be distinguished on the basis of their molecular weight (41). As mentioned before, SDS dissociates the TIMPs from the MMPs, which may result in a higher activity than in vivo. Because zymography only indicates whether the proenzyme displays in the presence of TIMP in vivo, it is uncertain how much activity such an active form would display in the presence of TIMP in vivo (41). Additionally, the refolding of MMPs after electrophoresis recovers only part of the original activity. Furthermore, the digestion of gelatin by pro-MMPs is somewhat reduced because the latent form still retains its propeptide domain (41).

\section{Gelatin Zymography}

Gelatin zymography is mainly used for the detection of the gelatinases, MMP-2 and MMP-9, respectively (Figure 2). It is extremely sensitive because levels of $10 \mathrm{pg}$ of MMP-2 can already be detected (43). It should be considered, however, that other MMPs, such as MMP-1, MMP-8, and MMP-13 can also lyse the substrate. This signal will probably be very weak because gelatin is not their preferential substrate $(44,45)$. For MMPs that do not show any activity on gelatin, modifications of the technique have been made for an improved detection. This is mainly done by incorporating a more suitable substrate into the gel, such as casein or collagen, or by enhancing the signal by adding heparin to the samples $(40,46,47)$.

\section{Casein Zymography}

Casein is a preferential substrate for the stromelysins including MMP-11, however, the native forms of MMP-11 show no caseinolytic activity (48-52). Casein zymography is also suitable for the detection of MMP-1, MMP-7, MMP-12, and MMP-13 (53-56). In addition, MMP-9 can be detected when present in high concentrations. Unfortunately, casein zymography is much less sensitive than gelatin zymography. Furthermore, casein migrates in the gel during electrophoresis due to its relatively low molecular weight $(23 \mathrm{kDa})$. This results in two clearly defined zones in the gel, the lower part that still contains excess casein and the upper part with less casein. The anodic migration of the casein is especially problematic in the case of MMPs that end up near the caseinmigration boundary, such as the latent and activated forms of MMP-7 (29 and $20 \mathrm{kDa}$, respectively; Reference 40). Prerunning the casein gel, allowing the excess casein to migrate out, can solve this. A second run of the gel does not cause any further migration of the casein, therefore eliminating its

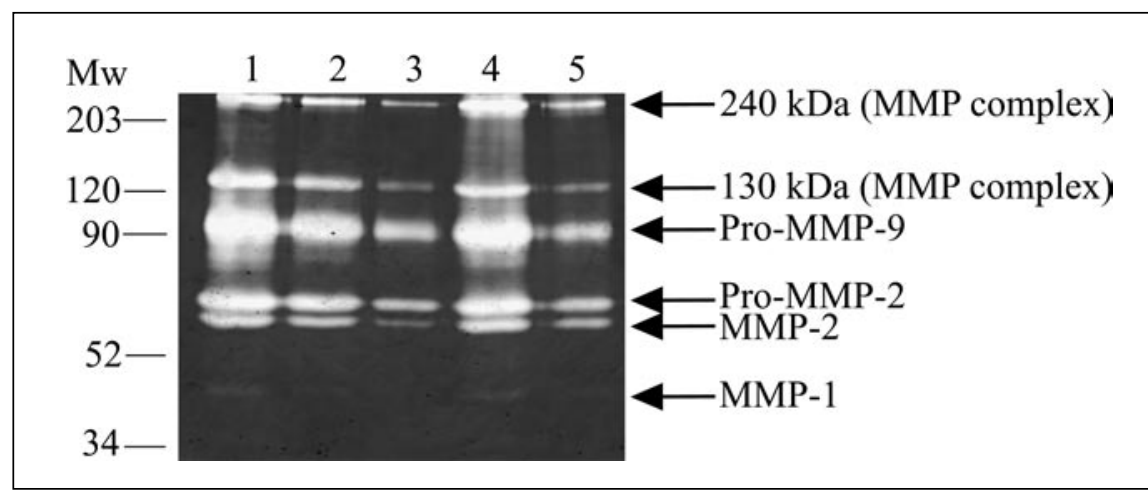

Figure 2. Gelatin zymography. MMPs are extracted from periodontal ligament, which is the ligament surrounding the root of a tooth, by three homogenization steps (lanes 1-3) and two heat extraction steps (lanes 4 and 5). Several MMPs are indicated such as MMP-1, MMP-2, and MMP-9. In addition, some complexes of MMPs are detected. The molecular weight standards [(Mw) Broad Range Marker; BioRad Laboratories, Hercules, CA, USA] are indicated (M.M. Bildt and P.A.M. Snoek-van Beurden, unpublished data). MMP, matrix metalloproteinase. interference with the MMP bands. The amount of casein remaining in the gel is still sufficient for the detection of MMPs. According to the literature, the minimal detectable amount of purified recombinant MMP-7 is $1 \mathrm{ng}$, but $8 \mathrm{ng}$ and more will give clear bands (40).

\section{Collagen Zymography}

Collagen zymography is mainly used for the detection of MMP-1 and MMP-13, but MMP-2 and MMP-9 can also be detected $(45,57,58)$. The incorporation of native collagen fibers in polyacrylamide gels appears unsuitable for zymography because of their complicated structure, but SDS disrupts most of the fibrillar organization of the collagen, allowing proteins to run into the gel. After running the zymogram, the exchange of SDS and Triton X-100 during incubation restores part of the original triple-helical conformation of collagen, allowing its degradation by collagenases. In collagen zymography, amounts of $10 \mathrm{pg}$ of pro-MMP1 and $0.1 \mathrm{pg}$ of active MMP-1 can be detected (47). The band intensity of 1 pg of active MMP-1 is about equivalent to that of $22 \mathrm{pg}$ of pro-MMP-1. This indicates the necessity to calibrate the signal of the pro-MMP-1 and active MMP-1 for accurate quantification (47).

\section{Heparin-Enhanced Substrate Zymography}

MMP-7 and the collagenases are hard to detect at low levels in casein or gelatin zymography. It is possible to detect MMP-7 in carboxymethylated (CM) transferrin zymography, which is occasionally used, but often the signal is very low (59-61). It is known that the extraction of MMPs from tissue in the presence of heparin results in an enhancement of MMP activity. The addition of heparin to the samples during or prior to electrophoresis also enhances MMP activity. The signal of intermediate and active MMP-7 can be enhanced about 5-fold by heparin in CM transferrin zymography and the detection of pro-MMP-7 can be enhanced even 20 -fold $(46,61)$. The mechanisms by which heparin seem to enhance MMP-7 activity in 
zymography are $(i)$ the induction of a conformational change, (ii) the facilitation of refolding, (iii) the reduction anchorage of the MMP in the gel (61). In the case of pro-MMP-7, heparinenhanced CM transferrin zymography can detect as little as $30 \mathrm{pg} / \mathrm{lane}$ compared to about $750 \mathrm{pg}$ without heparin. It is also possible to enhance the activity of MMP-1 and MMP-13 in gelatin zymography by adding heparin, which increases the sensitivity at least 5-fold (46).

The heparin forms a wide band or "heparin box" in the gel that spans a region of about $15-30 \mathrm{kDa}$, thus covering the MMP-7 forms with a molecular weight of 19 and $28 \mathrm{kDa}$ (Figure 3A) (46). Only when the MMPs end up in the heparin box, the enhancement is optimal. To determine the location of the heparin box, a separate regular sodium dodecyl sulfate polyacrylamide gel electrophoresis (SDS-PAGE) gel must be run, on which heparin can be detected with an azure A staining for glycosaminoglycans. Because the active and latent forms of MMP-1 and MMP-13 are in the range of 40-60 $\mathrm{kDa}$, heparin should be added to the lanes 20-30 min after the start of electrophoresis to ensure the co-migration of the MMPs and heparin (46). Prestained molecular weight standards are also added together with the heparin to indicate its position. For of autolysis, or (iv) the increase of

instance, when the 31-kDa band of the secondary molecular weight standards line up with the $66 \mathrm{kDa}$ band of the primary molecular weight standards, the heparin box will fall in the range $36-66 \mathrm{kDa}$ of the first molecular weight standards (Figure 3B; Reference 46). In conclusion, it is important to position the heparin box correctly to achieve reliable results. This makes the method more complex than other, more common forms of zymography.

\section{Reverse Zymography}

Four human TIMPs are known of which only TIMP-3 occurs in a glycosylated and an unglycosylated form. They can be detected by reverse zymography, which is a modification of zymography for MMPs (37). Besides gelatin, an MMP is also incorporated into the gel, usually MMP-2. During the activation step after electrophoresis, the MMP-2 only digests the gelatin in areas where TIMPs are absent. Thus, after staining, the gel will be colorless, except for the TIMP bands. In these bands, the TIMPs will inhibit MMP-2 activity by the formation of a 1:1 complex, and the gelatin will not be digested $(62,63)$. This results in blue TIMP bands against a colorless background (37). The SDS in the gel dissociates any TIMPs bound to MMPs, and thus the total amount of TIMPs in the sample is detected (63).
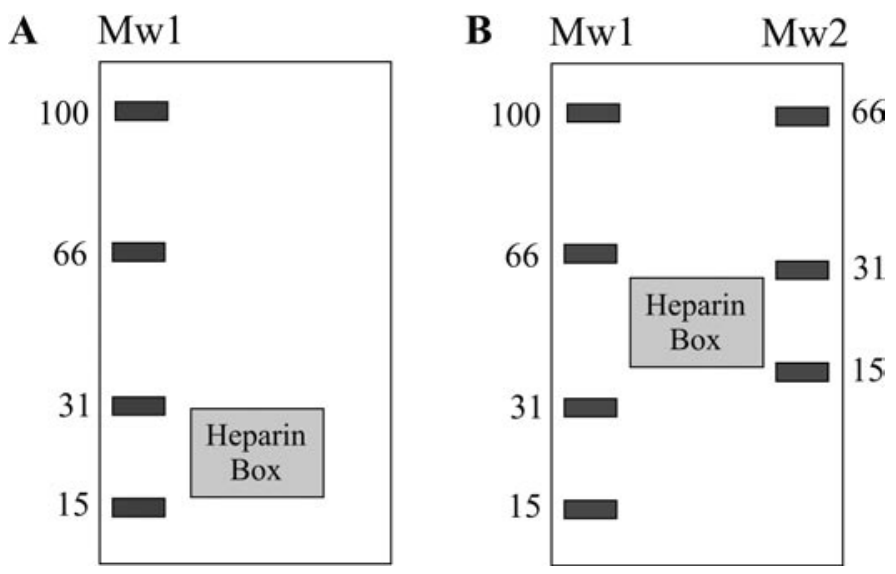

Figure 3. Heparin-enhanced zymography. The heparin box (light gray) must overlap the MMPs to enhance their activity. (A) The heparin box when heparin is added together with the samples and the primary standard (Mw1). (B) The heparin box when heparin is added after the start of electrophoresis together with the secondary standard (Mw2). The dark gray bands represent the molecular weight standards (Mw). MMP, matrix metalloproteinase.
The cheapest way to perform reverse zymography is to incorporate conditioned medium with MMPs in the gel next to gelatin (62). The conditioned medium should contain MMP-2 because all known TIMPs inhibit MMP-2 effectively (37). It is also possible to incorporate purified MMP-2, but this is far more expensive (64). A typical reverse zymogram with incorporated purified MMP-2 shows two sections, a small upper section (section 1) and a wider middle section (Figure 4A, section 2 and Figure 4C; Reference 42). Section 1 contains no MMP-2 because it is migrated further into the gel. This section is therefore stained blue because of the presence of gelatin. Thus, in this section, it is possible to detect MMP activity (42). Section 2 contains the MMP-2 and can be used for the detection of TIMPs (37). It is also possible to use conditioned medium that contains both MMP-2 and TIMP-2 activity. Due to the presence of SDS, the MMP-TIMP complexes in the conditioned medium will dissociate, and both will migrate through the gel according to their molecular weights (72 and $20 \mathrm{kDa}$, respectively; Reference 37). This results in three distinct sections on the Coomassie blue-stained gel, a narrow upper section (section 1), a wide middle section (section 2 ), and a narrow lower section (Figure 4B, section 3 and Figure 4D; References 37 and 42). Section 1 contains neither MMP-2 nor TIMP-2. Section 2 contains only MMP-2, while TIMP-2 has migrated further downwards because of its smaller molecular weight. Section 3 contains MMP-2 and the remaining TIMP-2. Section 2 is the analytical part of the gel and is used for the detection of TIMP activity $(37,62)$.

To obtain an increased effective range of the analytical section, the electrophoresis time can be prolonged. Furthermore, a longer stacking gel will increase the distance between any TIMP-2 from the sample and the TIMP2 from the conditioned medium (37). It is not recommended to use conditioned medium that contains other TIMPs than TIMP-2, such as TIMP-1 (28 $\mathrm{kDa}$ ), because its lower electrophoretic mobility yields a narrower analytical range in the gel (37). When conditioned medium is used that contains 
several MMPs, the background staining will consist of a pattern of horizontal regions, which renders the analysis of TIMPs inaccurate (42).

For the analysis of a reverse zymogram, it is necessary to discriminate between the TIMP bands and the proteins that are present in the sample, which will also be stained by the Coomassie Blue (37). Therefore, extracted tissue samples and total cell lysates from cultured cells can be particularly problematic. To avoid interference by endogenous proteins, samples should be electrophoresed at dilutions that do not allow detection of these proteins. Thus, a regular SDS-PAGE gel with the same sample should be run under identical conditions (37). Bands that appear in the reverse zymogram and are not visible in the regular SDS gel must be TIMPs (37). To obtain a reliable reverse zymogram, optimization of the gelatin and gelatinase concentration is required because this can dramatically increase the sensitivity (42). Recently, realtime zymography and reverse zymography were developed, which use a fluorescein isothiocyanate (FITC)labeled substrate (65). With these techniques, the substrate degradation can be monitored continuously with a transilluminator. Another advantage is the higher sensitivity that is achieved with lower amounts of substrates (65).
A

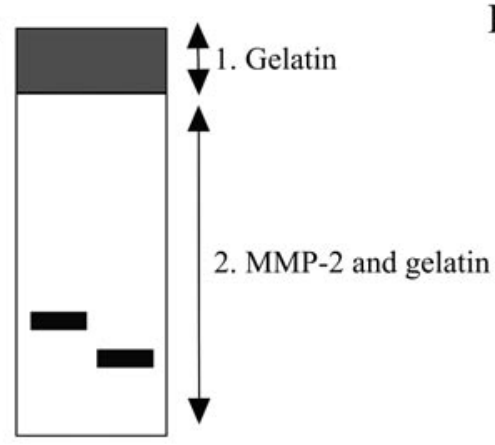

C

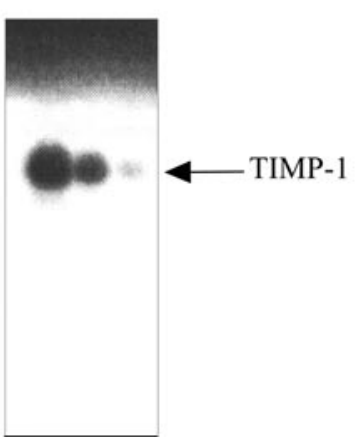

B

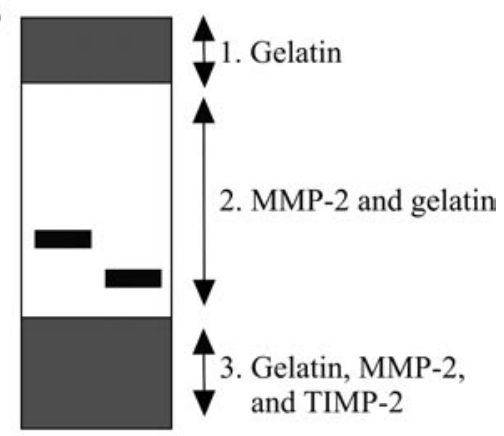

D

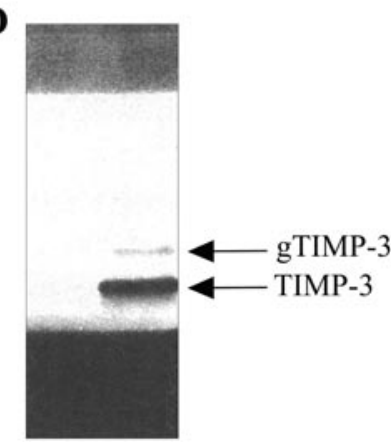

Figure 4. Reverse zymography. Overviews and examples of reverse zymography under different conditions. (A) An overview of a reverse zymogram with incorporated gelatin and purified MMP-2. Black bands represent TIMP activity. Section 1 contains only gelatin, and section 2 contains MMP-2 and digested gelatin. (B) An overview of a reverse zymogram with incorporated gelatin and conditioned medium containing both MMP-2 and TIMP-2. Black bands represent TIMP activity. Section 1 contains only gelatin, and section 2 contains MMP- 2 and digested gelatin. Section 3 contains gelatin, MMP-2, and TIMP-2 that have not migrated out of the gel. (A and B) Section 2 is used for the detection of TIMPs, which are visible as blue bands against a colorless background. (C) An example of reverse zymography with incorporated gelatin and purified MMP-2 showing TIMP-1. [Reprinted from Analytical Biochemistry, 244, Oliver et al., Quantitative reverse zymography: analysis of picogram amounts of metalloproteinase inhibitors using gelatinase A and B reverse zymograms, p. 161-166, copyright (1997), with permission from Elsevier (42)]. (D) An example of reverse zymography with incorporated gelatin and conditioned medium containing both MMP-2 and TIMP-2 showing both the glycosylated and unglycosylated form of TIMP-3. [Reprinted with permission from Hawkes et al., Zymography and reverse zymography for detecting MMPs, and TIMPs, p. 399-410. In I. Clark (Ed.), Matrix Metalloproteinases Protocols. Humana Press, Totowa, NJ, 2001 (37)]. MMP, matrix metalloproteinase; TIMPs, tissue inhibitors of metalloproteinases.

\section{In Situ Zymography}

In situ zymography allows the localization of MMPs in tissue sections $(26,66,67)$. It is an adaptation of substrate zymography that is suitable for frozen sections. The nature of the substrate dictates which MMP can be detected (68). In situ zymography is a relatively low-cost technique (68). Briefly, in situ zymography uses a substrate that is deposited on or under a frozen section of an unfixed tissue sample (Figure 5; Reference 68). During incubation, the substrate will be digested by the activated MMPs in a time- and dose-dependent manner (68). The degradation of the substrate is detected by light microscopy or fluorescence microscopy, depending on the type of substrate. For instance, gelatinolytic activity can be detected using a gelatincontaining photographic emulsion that is mixed with MMP activation buffer. MMPs present in the section can be detected due to exposure to ambient light during incubation and the subsequent photographic processing. The emulsion contains light-sensitive silver halide crystals that are evenly dispersed by gelatin. Photographic chemicals are allowed to reach the crystals when gelatin is not degraded by MMPs. This results in a chemical change of the crystals, leading to a black image. Chemicals are unable to penetrate the emulsion on spots where the gelatin is degraded, and white spots will appear. In conclusion, the MMP activity can be determined by light microscopy as white spots on a black background of undegraded substrate (Figure 5A; Reference 26). When using a fluorescent substrate, the degradation of the substrate causes loss of fluorescence, and the MMPs are then detected as black spots on a fluorescent background (Figure 5B; Reference 26). A more sensitive modification of this method uses a quenched fluorogenic substrate (69). When this substrate is cleaved, the MMPs are detected as strong fluorescent spots against a black background (Figure 5C; Reference 70).

With in situ zymography, only active MMPs are detected, but by activating latent MMPs (i.e., with APMA), both forms are visible (71). A limitation of this technique is that it may be difficult to discriminate between the different 
classes of MMPs (68). Additionally, not only can MMPs break down the substrates, but also serine, cysteine, or aspartic proteinases. Thus, it is essential to use control slides with appropriate MMP inhibitors (66). The main obstacle for in situ zymography is the scarcity of specific substrates or specific inhibitors, although more and more of these substrates and molecules will become available. A relatively new substrate is a biocompatible near-infrared fluorogenic (NIRF) MMP probe, consisting of a quenched near-infrared fluorochrome and an MMP-2 substrate on a nonimmunogenic backbone (72). When the substrate is cleaved, which occurs preferentially by MMP-2, the fluorescence intensity increases significantly. The probe can be used in live animals and can detect MMP activity within hours after injection (72). After placing the animal in a light-tight chamber, the fluorogenic activity inside the animal can be visualized with an imaging system (73). This technique has been developed to monitor MMP activity and their inhibition in tumors in vivo (72).
For the specific detection and imaging of MMP-7 in tumors, the polymer-based fluorogenic substrate PB-M7VIS has been developed (74).

Other new in situ zymography techniques are being developed, which have been named three-dimensional (3D), 4-D, and 5-D in situ zymography (75-77). In the 3-D technique, collagen with a quenched fluorescent label is copolymerized together with the cells in a 3-D collagen lattice. The degradation of collagen by MMPs from live cells is detected by measuring the fluorescent signal with confocal microscopy $(76,77)$. The monitoring of the signal in the collagen lattices over time produces a 4-D technique (77). The use of more than one fluorochrome to determine the localization of several MMPs in time generates 5-D information (http://www. ichc2004.org/PdfFolder/AbstractsAuthorIndex.pdf; SP8). The advantages of these techniques over normal in situ zymography are the possibility to monitor cell migration and cell shape changes in addition to the progression of substrate degradation (75-77).

\section{PROBLEMS}

\section{MMP Extraction}

In media obtained from cell culture, it is relatively easy to detect MMPs and TIMPs. However, the extraction and analysis of MMPs and TIMPs from tissues are much more difficult. In the first place, the amount of MMPs and TIMPs in tissues is about 50 times lower than those found in conditioned medium (41). Secondly, they are difficult to extract from tissues, and it is never certain whether all MMPs and TIMPs are extracted. Moreover, several MMPs, such as MMP-1, MMP2 , and MMP-9, are tightly bound to the ECM (41). Another disadvantage of tissue extraction is the preclusion of the localization of MMPs. In addition, the extraction procedure can activate MMPs, but MMPs can also be inactivated by binding with their respective inhibitors, which may have been localized in distinct compartments in the intact cells or tissue (68). Specific MMPs or TIMPs localized in a small

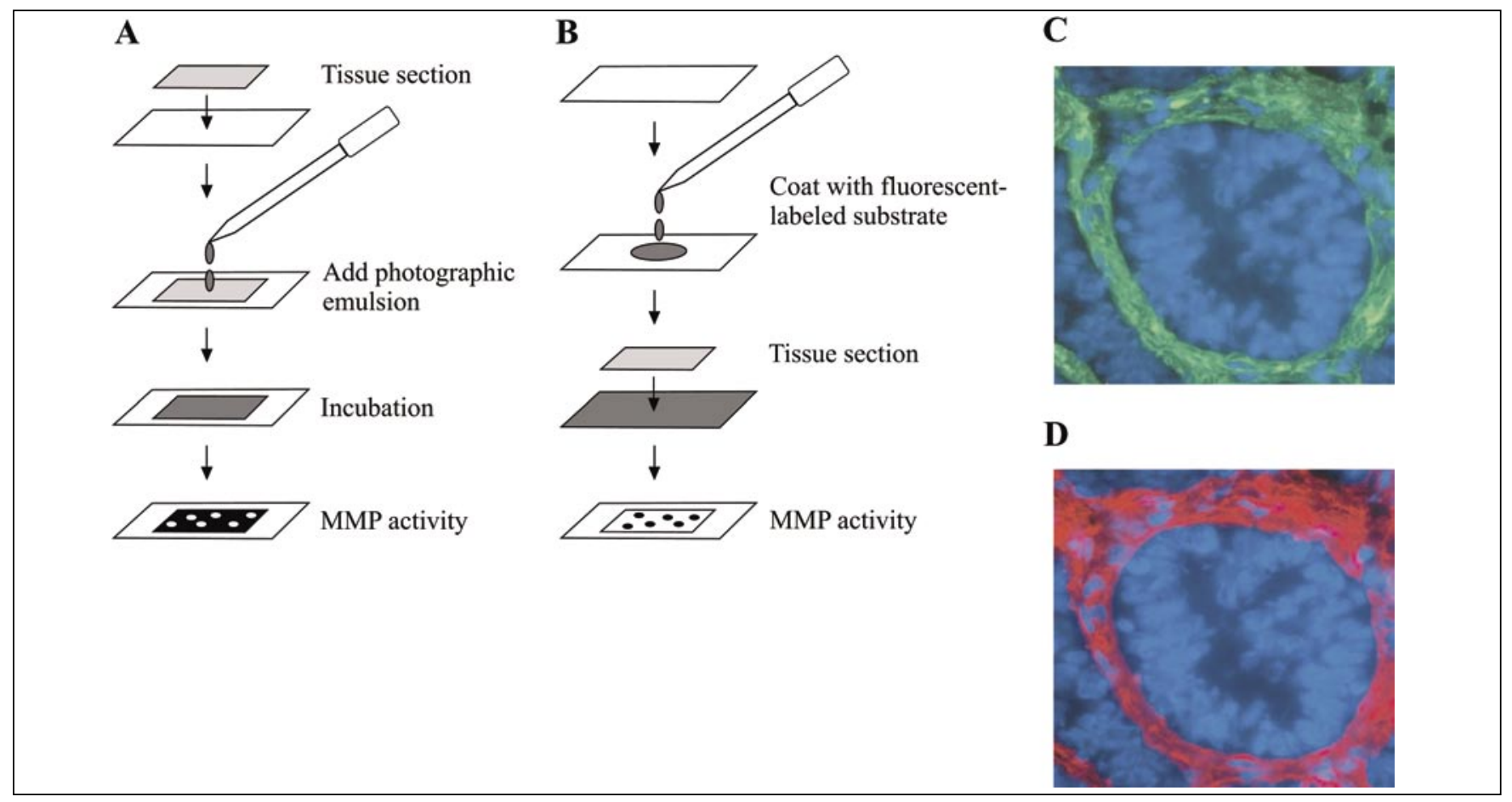

Figure 5. In situ zymography. An overview and an example of in situ zymography are shown. In situ zymography using (A) a photographic emulsion and (B) a fluorescent substrate. (C) An example of in situ zymography using quenched fluorogenic gelatin. MMP activity is shown as green fluorescence, and the section is counterstained with DAPI (70). (D) The red signal indicates the immunolocalization of MMP-2. It shows a similar localization pattern as the fluorescent signal in Figure 5C, indicating that the gelatin degradation is caused by MMP-2. The section is counterstained with DAPI. [Figure 5, C and D, is reproduced with permission from Mook et al., In situ localization of gelatinolytic Activity in the extracellular matrix of metastases of colon cancer in rat liver using quenched fluorogenic DQ-gelatin. Journal of Histochemistry and Cytochemistry 51:821-829, 2003 (70)]. MMP, matrix metalloproteinase. 
part of the tissue may not be detected because of its dilution in the entire tissue extract (68). Because of these problems, it is difficult to determine the actual activity of MMPs in tissues. To localize MMPs in tissue in the presence of TIMPs, using in situ zymography is recommended. This technique reflects the endogenous balance of MMPs and TIMPs in the tissue, although quantification is not possible (68).

\section{Substrate Zymography}

Sample preparation is very important when performing a zymography. The samples should not be boiled because the MMPs will lose their activity. Moreover, the addition of $\beta$-mercaptoethanol to the sample buffer is not recommended because it breaks the disulphide bonds of the MMPs. After the zymography, the MMPs will not be able to refold again, which causes a dramatic decrease in their activity (37). It should be considered that the nonreducing conditions lead to slightly different migration characteristics of the MMPs and TIMPs compared with Western blot analysis (37). It is also important to consider that SDS dissociates MMPs from TIMPs, and thus only indicates the presence of MMPs and TIMPs, but not the actual activity within the tissue.

The staining and destaining of the zymogram can lead to overstaining, which causes loss of sensitivity. Alternatively, it is possible to destain the gel too much, which bleaches the bands and makes them unsuitable for quantification (38). Simply combining the staining and destaining solutions can solve this problem. It will also yield a fast and reproducible staining (38). This single-step staining protocol was successfully used for the analysis of MMP-2 and MMP-9 in gelatin zymography and for MMP7 in casein zymography (38). Testing substrates from various sources might further increase the sensitivity of zymography or reverse zymography. Substrates can differ considerably in performance, especially in reverse zymography (37). For every new substrate, it is necessary to determine the optimal substrate concentration, the most suitable conditioned medium, and the optimal running and developing conditions $(37,42)$. Despite the optimization, specific MMPs might still not be detected because zymography is sometimes just not sensitive enough. In those cases, other assays might be more suitable, such as enzyme-linked immunosorbent assay (ELISA) or Western blot analysis. For example, MMP-8 is difficult to detect with zymography, but with other techniques it might be possible to measure protein levels $(78,79)$.

In situ zymography is used for the identification and microscopic localization of MMPs within sections of unfixed frozen tissues. The MMPs are detected using a photographic emulsion or a fluorescent substrate. A disadvantage of the photographic method is the difficulty to standardize the method (80). The slides cannot be coverslipped and are therefore more sensitive to variations in humidity during the incubation. Additionally, the thickness of the emulsion layer might be uneven and thereby reduce the quality of the results (80). In contrast, with the fluorescent substrate, the substrate is deposited on the slide before applying the section. In this way, poorly coated glass slides can be detected by microscopic inspection before placing the tissue sections on the slides (80). However, the sensitivity of this method is lower because higher levels of enzymatic activity are required to produce spots large enough for detection (68). A more sensitive approach, which is often used nowadays, uses a highly quenched fluorescent substrate that fluoresces only after degradation. The enzymatic activity is observed as a fluorescent area against a darker, low fluorescent background (69).

\section{PROBLEMS WITH THE ANALYSIS}

The identification of MMPs and TIMPs is often achieved by comparison with known molecular weight standards (37). One should be aware that some commercially available molecular weight standards contain a reducing agent. When these standards are used under nonreducing conditions, they may indicate different molecular weights (37). For a definite identification of MMPs and TIMPs, one must perform Western blot analysis using specific antibodies. Because zymography is much more sensitive than Western blot analysis, it might be difficult to find antibodies that are sensitive enough to detect small amounts of MMPs and TIMPs.

MMPs and TIMPs can be quantified after zymography using densitometry. The amounts of MMPs or TIMPs are determined by comparison with a standard curve of a purified enzyme (47). However, complexes of MMPs might occur that complicate the analysis. MMP-9 can be associated with a $25-\mathrm{kDa}$ protein (microglobulin), giving a band at $125 \mathrm{kDa}$ and a dimer at $215 \mathrm{kDa}$. These complexes are not dissociated in zymography (81). In Figure 2, a band is found at $240 \mathrm{kDa}$ that might represent a multimer or pro-MMP-9 (82). Also, several MMPs together can form complexes that can only be identified with specific antibodies in Western blot analysis.

Using in situ zymography, it is often not possible to discriminate between different MMPs because the substrates are usually degraded by more than one MMP. Specific MMPs should be identified by a complementary technique such as immunohistochemistry for valid conclusions (68). The immunolocalization of MMPs can be compared with the localization pattern of the in situ zymography, which should be preferably performed on the same section or on serial sections (66). Some very specific substrates for MMP-1, MMP-7, MMP8, and MMP-13 are currently available, which are generally fluorescent peptides $(45,83,88)$. To summarize, although the limitations of the zymographical techniques make it sometimes difficult to interpret the data, it is the most suitable technique to analyze MMPs.

\section{CONCLUSION}

The balance between MMPs and TIMPs regulates tissue remodeling under normal conditions. A deregulation of this balance is a characteristic of pathological conditions involving extensive tissue degradation. To analyze the role of various MMPs and TIMPs under normal and pathological conditions, reliable detection methods such as zymography are required. This technique is a highly sensitive method for the analysis of MMPs and TIMPs. Various adaptations of substrate zymography are currently available, 
which are generally cheap and easy to perform. Most of these methods are very sensitive, but this also depends on the specific MMP or TIMP under study. Optimization of the subsequent steps is necessary to obtain high sensitivity and accuracy. Additionally, modifications are being developed that may lead to faster and more reliable techniques such as the real-time dual zymography in which fluorescent gelatin and casein are incorporated in the same gel (84). For in situ zymography, newer and more sensitive substrates are being developed to discriminate between the different MMPs. The improvement of sensitivity and accuracy of zymographical methods will further enhance its value for research purposes and for the development of new diagnostic techniques and therapies for conditions that involve extensive tissue degradation.

\section{COMPETING INTERESTS STATEMENT}

The authors declare no competing interests.

\section{REFERENCES}

1.Bode, W. and K. Maskos. 2003. Structural basis of the matrix metalloproteinases and their physiological inhibitors, the tissue inhibitors of metalloproteinases. Biol. Chem. 384:863-872.

2.Brew, K., D. Dinakarpandian, and H. Nagase. 2000. Tissue inhibitors of metalloproteinases: evolution, structure and function. Biochim. Biophys. Acta 1477:267-283.

3.Baker, A.H., D.R. Edwards, and G. Murphy. 2002. Metalloproteinase inhibitors: biological actions and therapeutic opportunities. J. Cell Sci. 115:3719-3727.

4.Bode, W., C. Fernandez-Catalan, F. Grams, F.X. Gomis-Ruth, H. Nagase, H. Tschesche, and K. Maskos. 1999. Insights into MMP-TIMP interactions. Ann. NY Acad. Sci. 878:73-91.

5.Pilcher, B.K., M. Wang, X.J. Qin, W.C. Parks, R.M. Senior, and H.G. Welgus. 1999. Role of matrix metalloproteinases and their inhibition in cutaneous wound healing and allergic contact hypersensitivity. Ann. NY Acad. Sci. 878:12-24

6.Chin, J.R. and Z. Werb. 1997. Matrix metalloproteinases regulate morphogenesis, migration and remodeling of epithelium, tongue skeletal muscle and cartilage in the mandibular arch. Development 124:1519-1530.

7.Heikinheimo, K. and T. Salo. 1995. Expression of basement membrane type IV collagen and type IV collagenases (MMP-2 and MMP-
9) in human fetal teeth. J. Dent. Res. 74:12261234.

8.Steffensen, B., L. Hakkinen, and H. Larjava. 2001. Proteolytic events of wound-healing-coordinated interactions among matrix metalloproteinases (MMPs), integrins, and extracellular matrix molecules. Crit. Rev. Oral. Biol. Med. 12:373-398.

9.Konttinen, Y.T., M. Ainola, H. Valleala, J. Ma, H. Ida, J. Mandelin, R.W. Kinne, S. Santavirta et al. 1999. Analysis of 16 dif- ferent matrix metalloproteinases (MMP-1 to MMP-20) in the synovial membrane: different profiles in trauma and rheumatoid arthritis. Ann. Rheum. Dis. 58:691-697.

10.Tetlow, L.C., D.J. Adlam, and D.E. Woolley. 2001. Matrix metalloproteinase and proinflammatory cytokine production by chondrocytes of human osteoarthritic cartilage: associations with degenerative changes. Arthritis Rheum. 44:585-594.

11.Bar-Or, A., R.K. Nuttall, M. Duddy, A. Al- 
ter, H.J. Kim, I. Ifergan, C.J. Pennington, P. Bourgoin, et al. 2003. Analyses of all matrix metalloproteinase members in leukocytes emphasize monocytes as major inflammatory mediators in multiple sclerosis. Brain 126:2738-2749.

12.Visse, R. and H. Nagase. 2003. Matrix metalloproteinases and tissue inhibitors of metalloproteinases: structure, function, and biochemistry. Circ. Res. 92:827-839.

13.Ahokas, K., J. Lohi, H. Lohi, O. Elomaa, M.L. Karjalainen-Lindsberg, J. Kere, and U. Saarialho-Kere. 2002. Matrix metalloproteinase-21, the human orthologue for XMMP, is expressed during fetal development and in cancer. Gene 301:31-41.

14.Pendas, A.M., V. Knauper, X.S. Puente, E. Llano, M.G. Mattei, S. Apte, G. Murphy, and C. Lopez-Otin. 1997. Identification and characterization of a novel human matrix metalloproteinase with unique structural characteristics, chromosomal location, and tissue distribution. J. Biol. Chem. 272:4281-4286.

15.Nagase, H. and J.F. Woessner Jr. 1999. Matrix metalloproteinases. J. Biol. Chem. 274:21491-21494.

16.Stamenkovic, I. 2003. Extracellular matrix remodelling: the role of matrix metalloproteinases. J. Pathol. 200:448-464

17.Kapila, S. and J.J. Chen. 2000. Matrix metalloproteinases in orthodontic tooth movement: principles and potential applications, $\mathrm{p}$. 107-117. In Z. Davidovitch and J. Mah (Eds.), Biological Mechanisms of Tooth Movement and Craniofacial Adaptation. Harvard Society for the Advancement of Orthodontics, Boston, MA.

18.Salmela, M.T., M.L. Karjalainen-Lindsberg, P. Puolakkainen, and U. SaarialhoKere. 2001. Upregulation and differential expression of matrilysin (MMP-7) and metalloelastase (MMP-12) and their inhibitors TIMP-1 and TIMP-3 in Barrett's oesophageal adenocarcinoma. Br. J. Cancer 85:383-392.

19.Kerkela, E. and U. Saarialho-Kere. 2003. Matrix metalloproteinases in tumor progression: focus on basal and squamous cell skin cancer. Exp. Dermatol. 12:109-125.

20.Marchenko, G.N., B.I. Ratnikov, D.V. Rozanov, A. Godzik, E.I. Deryugina, and A.Y. Strongin. 2001. Characterization of matrix metalloproteinase-26, a novel metalloproteinase widely expressed in cancer cells of epithelial origin. Biochem. J. 356:705-718.

21.Bode, W. 1995. A helping hand for collagenases: the haemopexin-like domain. Structure 3:527-530.

22.Jones, C.B., D.C. Sane, and D.M. Herrington. 2003. Matrix metalloproteinases. A review of their structure and role in acute coronary syndrome. Cardiovasc. Res. 59:812823

23.Stracke, J.O., A.J. Fosang, K. Last, F.A. Mercuri, A.M. Pendas, E. Llano, R. Perris, P.E. Di Cesare, et al. 2000. Matrix metalloproteinases 19 and 20 cleave aggrecan and cartilage oligomeric matrix protein (COMP). FEBS Lett. 478:52-56

24.Gronski, T.J., Jr., R.L. Martin, D.K. Kobayashi, B.C. Walsh, M.C. Holman, M. Huber, H.E. Van Wart, and S.D. Shapiro. 1997. Hydrolysis of a broad spectrum of extracel- lular matrix proteins by human macrophage elastase. J. Biol. Chem. 272:12189-12194.

25.Parks, W.C. and S.D. Shapiro. 2001. Matrix metalloproteinases in lung biology. Respir. Res. 2:10-19.

26.Galis, Z.S., G.K. Sukhova, M.W. Lark, and P. Libby. 1994. Increased expression of matrix metalloproteinases and matrix degrading activity in vulnerable regions of human atherosclerotic plaques. J. Clin. Invest. 94:24932503.

27.Springman, E.B., E.L. Angleton, H. Birkedal-Hansen, and H.E. Van Wart. 1990. Multiple modes of activation of latent human fibroblast collagenase: evidence for the role of a Cys73 active-site zinc complex in latency and a "cysteine switch" mechanism for activation. Proc. Natl. Acad. Sci. USA 87:364-368.

28.Van Wart, H.E. and H. Birkedal-Hansen. 1990. The cysteine switch: a principle of regulation of metalloproteinase activity with potential applicability to the entire matrix metalloproteinase gene family. Proc. Natl. Acad. Sci. USA 87:5578-5582.

29.Park, A.J., L.M. Matrisian, A.F. Kells, R. Pearson, Z.Y. Yuan, and M. Navre. 1991. Mutational analysis of the transin (rat stromelysin) autoinhibitor region demonstrates a role for residues surrounding the "cysteine switch.” J. Biol. Chem. 266:1584-1590.

30.Gomez, D.E., D.F. Alonso, H. Yoshiji, and U.P. Thorgeirsson. 1997. Tissue inhibitors of metalloproteinases: structure, regulation and biological functions. Eur. J. Cell Biol. 74:111122.

31.Kevorkian, L., D.A. Young, C. Darrah, S.T. Donell, L. Shepstone, S. Porter, S.M. Brockbank, D.R. Edwards, et al. 2004. Expression profiling of metalloproteinases and their inhibitors in cartilage. Arthritis Rheum. 50:131-141

32.Coussens, L.M., B. Fingleton, and L.M. Matrisian. 2002. Matrix metalloproteinase inhibitors and cancer: trials and tribulations. Science 295:2387-2392.

33.Kioi, M., K. Yamamoto, S. Higashi, N. Koshikawa, K. Fujita, and K. Miyazaki. 2003. Matrilysin (MMP-7) induces homotypic adhesion of human colon cancer cells and enhances their metastatic potential in nude mouse model. Oncogene 22:8662-8670.

34.Leeman, M.F., S. Curran, and G.I. Murray. 2003. New insights into the roles of matrix metalloproteinases in colorectal cancer development and progression. J. Pathol. 201:528534.

35.Galis, Z.S. and J.J. Khatri. 2002. Matrix metalloproteinases in vascular remodeling and atherogenesis: the good, the bad, and the ugly. Circ. Res. 90:251-262.

36.Creemers, E.E., J.P. Cleutjens, J.F. Smits, and M.J. Daemen. 2001. Matrix metalloproteinase inhibition after myocardial infarction: a new approach to prevent heart failure? Circ. Res. 89:201-210.

37.Hawkes, S.P., H. Li, and G.T. Taniguchi. 2001. Zymography and reverse zymography for detecting MMPs, and TIMPs, p. 399-410. In I. Clark (Ed.), Matrix Metalloproteinases Protocols. Humana Press, Totowa, NJ.

38.Leber, T.M. and F.R. Balkwill. 1997. Zymography: a single-step staining method for quantitation of proteolytic activity on substrate gels. Anal. Biochem. 249:24-28

39.Heussen, C. and E.B. Dowdle. 1980. Electrophoretic analysis of plasminogen activators in polyacrylamide gels containing sodium dodecyl sulfate and copolymerized substrates. Anal. Biochem. 102:196-202.

40.Fernandez-Resa, P., E. Mira, and A.R. Quesada. 1995. Enhanced detection of casein zymography of matrix metalloproteinases. Anal. Biochem. 224:434-435.

41.Woessner, J.F., Jr. 1995. Quantification of matrix metalloproteinases in tissue samples. Methods Enzymol. 248:510-528.

42.Oliver, G.W., J.D. Leferson, W.G. StetlerStevenson, and D.E. Kleiner. 1997. Quantitative reverse zymography: analysis of picogram amounts of metalloproteinase inhibitor using gelatinase $\mathrm{A}$ and $\mathrm{B}$ reverse zymograms. Anal. Biochem. 244:161-166.

43.Kleiner, D.E. and W.G. Stetler-Stevenson. 1994. Quantitative zymography: detection of picogram quantities of gelatinases. Anal. Biochem. 218:325-329.

44.Bjornland, K., J.O. Winberg, O.T. Odegaard, E. Hovig, T. Loennechen, A.O. Aasen, O. Fodstad, and G.M. Maelandsmo. 1999. S100A4 involvement in metastasis: deregulation of matrix metalloproteinases and tissue inhibitors of matrix metalloproteinases in osteosarcoma cells transfected with an anti-S100A4 ribozyme. Cancer Res. 59:47024708 .

45.Knauper, V., C. Lopez-Otin, B. Smith, G. Knight, and G. Murphy. 1996. Biochemical characterization of human collagenase-3. J. Biol. Chem. 271:1544-1550.

46.Yu, W.H. and J.F. Woessner, Jr. 2001 Heparin-enhanced zymographic detection of matrilysin and collagenases. Anal. Biochem. 293:38-42.

47.Gogly, B., N. Groult, W. Hornebeck, G. Godeau, and B. Pellat. 1998. Collagen zymography as a sensitive and specific technique for the determination of subpicogram levels of interstitial collagenase. Anal. Biochem. 255:211-216.

48.Chin, J.R., G. Murphy, and Z. Werb. 1985 Stromelysin, a connective tissue-degrading metalloendopeptidase secreted by stimulated rabbit synovial fibroblasts in parallel with collagenase. Biosynthesis, isolation, characterization, and substrates. J. Biol. Chem 260:12367-12376.

49.Rawdanowicz, T.J., A.L. Hampton, H. Nagase, D.E. Woolley, and L.A. Salamonsen. 1994. Matrix metalloproteinase production by cultured human endometrial stromal cells: identification of interstitial collagenase, gelatinase-A, gelatinase-B, and stromelysin-1 and their differential regulation by interleukin-1 alpha and tumor necrosis factor-alpha. J. Clin. Endocrinol. Metab. 79:530-536.

50.Nakamura, H., Y. Fujii, E. Ohuchi, E. Yamamoto, and Y. Okada. 1998. Activation of the precursor of human stromelysin 2 and its interactions with other matrix metalloproteinases. Eur. J. Biochem. 253:67-75.

51.Windsor, L.J., H. Grenett, B. BirkedalHansen, M.K. Bodden, J.A. Engler, and H. Birkedal-Hansen. 1993. Cell type-specific regulation of SL-1 and SL-2 genes. Induction 
of the SL-2 gene but not the SL-1 gene by human keratinocytes in response to cytokines and phorbolesters. J. Biol. Chem. 268:1734117347.

52.Murphy, G., J.P. Segain, M. O'Shea, M. Cockett, C. Ioannou, O. Lefebvre, P. Chambon, and P. Basset. 1993. The 28-kDa N-terminal domain of mouse stromelysin- 3 has the general properties of a weak metalloproteinase. J. Biol. Chem. 268:15435-15441.

53.Huang, Y., M. Mironova, and M.F. LopesVirella. 1999. Oxidized LDL stimulates matrix metalloproteinase-1 expression in human vascular endothelial cells. Arterioscler. Thromb. Vasc. Biol. 19:2640-2647.

54.Miyazaki, K., Y. Hattori, F. Umenishi, H. Yasumitsu, and M. Umeda. 1990. Purification and characterization of extracellular matrix-degrading metalloproteinase, matrin (pump-1), secreted from human rectal carcinoma cell line. Cancer Res. 50:7758-77564.

55.Gardner, H., A. Broberg, A. Pozzi, M. Laato, and J. Heino. 1999. Absence of integrin alphalbeta1 in the mouse causes loss of feedback regulation of collagen synthesis in normal and wounded dermis. J. Cell Sci. 112:263-272.

56.Curci, J.A., S. Liao, M.D. Huffman, S.D. Shapiro, and R.W. Thompson. 1998. Expression and localization of macrophage elastase (matrix metalloproteinase-12) in abdominal aortic aneurysms. J. Clin. Invest. 102:1900-1910.

57.Koskinen, S.O., A.M. Ahtikoski, J. Komulainen, M.K. Hesselink, M.R. Drost, and T.E. Takala. 2002. Short-term effects of forced eccentric contractions on collagen synthesis and degradation in rat skeletal muscle. Pflugers Arch. 444:59-72.

58.Nishikawa, M., Y. Yamaguchi, K. Yoshitake, and Y. Saeki. 2002. Effects of TNFalpha and prostaglandin E2 on the expression of MMPs in human periodontal ligament fibroblasts. J. Periodontal Res. 37:167-176.

59.Nagase, H. 1995. Human stromelysins 1 and 2. Methods Enzymol. 248:449-470.

60.Hao, L., M. Du, A. Lopez-Campistrous, and C. Fernandez-Patron. 2004. Agonistinduced activation of matrix metalloproteinase-7 promotes vasoconstriction through the epidermal growth factor-receptor pathway. Circ. Res. 94:68-76.

61.Yu, W.H. and J.F. Woessner, Jr. 2000. Heparan sulfate proteoglycans as extracellular docking molecules for matrilysin (matrix metalloproteinase 7). J. Biol. Chem. 275:41834191.

62.Staskus, P.W., F.R. Masiarz, L.J. Pallanck, and S.P. Hawkes. 1991. The 21-kDa protein is a transformation-sensitive metalloproteinase inhibitor of chicken fibroblasts. J. Biol. Chem. 266:449-454.

63.Riley, S.C., R. Leask, F.C. Denison, K. Wisely, A.A. Calder, and D.C. Howe. 1999. Secretion of tissue inhibitors of matrix metalloproteinases by human fetal membranes, decidua and placenta at parturition. J. Endocrinol. 162:351-359.

64.Mandler, R.N., J.D. Dencoff, F. Midani, C.C. Ford, W. Ahmed, and G.A. Rosenberg. 2001. Matrix metalloproteinases and tissue inhibitors of metalloproteinases in cerebrospinal fluid differ in multiple sclerosis and Devic's neuromyelitis optica. Brain 124:493-498.

65.Hattori, S., H. Fujisaki, T. Kiriyama, T. Yokoyama, and S. Irie. 2002. Real-time zymography and reverse zymography: a method for detecting activities of matrix metalloproteinases and their inhibitors using FITC-labeled collagen and casein as substrates. Anal. Biochem. 301:27-34.

66.Frederiks, W.M. and O.R. Mook. 2004. Metabolic mapping of proteinase activity with emphasis on in situ zymography of gelatinases: review and protocols. J. Histochem. Cytochem. 52:711-722.

67.George, S.J. and J.L. Johnson. 2001. In situ zymography, p. 411-415. In I. Clark (Ed.), Matrix Metalloproteinases Protocols. Humana Press, Totowa, NJ.

68.Yan, S.J. and E.A. Blomme. 2003. In situ zymography: a molecular pathology technique to localize endogenous protease activity in tissue sections. Vet. Pathol. 40:227-236.

69.Oh, L.Y., P.H. Larsen, C.A. Krekoski, D.R. Edwards, F. Donovan, Z. Werb, and V.W. Yong. 1999. Matrix metalloproteinase-9/gelatinase $\mathrm{B}$ is required for process outgrowth by oligodendrocytes. J. Neurosci. 19:8464-8475.

70.Mook, O.R., C. Van Overbeek, E.G. Ackema, F. Van Maldegem, and W.M. Frederiks. 2003. In situ localization of gelatinolytic activity in the extracellular matrix of metastases of colon cancer in rat liver using quenched fluorogenic DQ-gelatin. J. Histochem. Cytochem. 51:821-829.

71.Mungall, B.A. and C.C. Pollitt. 2001. In situ zymography: topographical considerations. J. Biochem. Biophys. Methods 47:169-176.

72.Bremer, C., C.H. Tung, and R. Weissleder. 2001. In vivo molecular target assessment of matrix metalloproteinase inhibition. Nat. Med. 7:743-748

73.Bremer, C., S. Bredow, U. Mahmood, R. Weissleder, and C.H. Tung. 2001. Optical imaging of matrix metalloproteinase- 2 activity in tumors: feasibility study in a mouse model. Radiology 221:523-529.

74. McIntyre, J.O., B. Fingleton, K.S. Wells, D.W. Piston, C.C. Lynch, S. Gautam, and L.M. Matrisian. 2004. Development of a novel fluorogenic proteolytic beacon for in vivo detection and imaging of tumour-associated matrix metalloproteinase-7 activity. Biochem. J. 377:617-628

75.Wolf, K., R. Muller, S. Borgmann, E.B. Brocker, and P. Friedl. 2003. Amoeboid shape change and contact guidance: T-lymphocyte crawling through fibrillar collagen is independent of matrix remodeling by MMPs and other proteases. Blood 102:3262-3269.

76.Sameni, M., K. Moin, and B.F. Sloane. 2000. Imaging proteolysis by living human breast cancer cells. Neoplasia 2:496-504.

77.Sameni, M., J. Dosescu, and B.F. Sloane. 2001. Imaging proteolysis by living human glioma cells. Biol. Chem. 382:785-788.

78.Okuda, K., A. Miyazaki, M. Momose, M. Murata, T. Nomura, T. Kubota, L.F. Wolff, and H. Yoshie. 2001. Levels of tissue inhibitor of metalloproteinases- 1 and matrix metalloproteinases-1 and -8 in gingival crevicular fluid following treatment with enamel matrix derivative (EMDOGAIN). J. Periodontal Res.
36:309-316.

79.Kiili, M., S.W. Cox, H.W. Chen, J. Wahlgren, P. Maisi, B.M. Eley, T. Salo, and T. Sorsa. 2002. Collagenase-2 (MMP-8) and collagenase-3 (MMP-13) in adult periodontitis: molecular forms and levels in gingival crevicular fluid and immunolocalisation in gingival tissue. J. Clin. Periodontol 29:224-232.

80.Galis, Z.S., G.K. Sukhova, and P. Libby. 1995. Microscopic localization of active proteases by in situ zymography: detection of matrix metalloproteinase activity in vascular tissue. FASEB J. 9:974-980.

81.Triebel, S., J. Blaser, H. Reinke, and $\mathbf{H}$. Tschesche. 1992. A $25 \mathrm{kDa}$ alpha 2-microglobulin-related protein is a component of the $125 \mathrm{kDa}$ form of human gelatinase. FEBS Lett. 314:386-388.

82.Goldberg, G.I., A. Strongin, I.E. Collier, L.T. Genrich, and B.L. Marmer. 1992. Interaction of 92-kDa type IV collagenase with the tissue inhibitor of metalloproteinases prevents dimerization, complex formation with interstitial collagenase, and activation of the proenzyme with stromelysin. J. Biol. Chem. 267:4583-4591.

83.Netzel-Arnett, S., S.K. Mallya, H. Nagase, H. Birkedal-Hansen, and H.E. Van Wart. 1991. Continuously recording fluorescent assays optimized for five human matrix metalloproteinases. Anal. Biochem. 195:86-92.

84. Watanabe, K. and S. Hattori. 2002. Realtime dual zymographic analysis of matrix metalloproteinases using fluorescein-isothiocyante-labeled gelatin and Texas-red-labeled casein. Anal. Biochem. 307:390-392.

85.Wang, X., J. Yi, J. Lei, and D. Pei. 1999. Expression, purification and characterization of recombinant mouse MT5-MMP protein products. FEBS Lett. 462:261-266.

86.English, W.R., G. Velasco, J.O. Stracke, V. Knauper, and G. Murphy. 2001. Catalytic activities of membrane-type 6 matrix metalloproteinase (MMP25). FEBS Lett. 491:137142

87.Gioia, M., G.F. Fasciglione, S. Marini, S. D'Alessio, G. De Sanctis, O. Diekmann, M. Pieper, V. Politi, et al. 2002. Modulation of the catalytic activity of neutrophil collagenase MMP-8 on bovine collagen I. Role of the activation cleavage and of the hemopexin-like domain. J. Biol. Chem. 277:23123-23130.

88.McGeehan, G.M., D.M. Bickett, M. Green, D. Kassel, J.S. Wiseman, and J. Berman. 1994. Characterization of the peptide substrate specificities of interstitial collagenase and 92 $\mathrm{kDa}$ gelatinase. Implications for substrate optimization. J. Biol. Chem. 269:32814-32820.

Address correspondence to:

J.W. Von den Hoff

University Medical Centre Nijmegen Department of Orthodontics and Oral Biology

P.O. Box 9101

$6500 \mathrm{HB}$, Nijmegen, The Netherlands

e-mail: h.vondenhoff@dent.umcn.nl 